\title{
HEAT TRANSFER AND TEMPERATURE DISTRI- BUTIONS IN AN AGITATED TANK EQUIPPED WITH HELICAL RIBBON IMPELLER
}

\author{
Masafumi KURIYAMA, MasaKatsu OHTA, \\ KINYA YANAGAWA, KunIO ARAI AND SHOZABURo SAITO \\ Department of Chemical Engineering, \\ Tohoku University, Sendai 980
}

\begin{abstract}
Temperature distributions of fluid in an agitated tank equipped with a helical ribbon impeller are visualized by means of liquid crystal particles and the relation between temperature distribution and circulation flow is observed. It is concluded that non-uniformities in temperature in an agitated tank should not be neglected in the laminar flow region and that, in this case, a flow model realistic enough to represent the actual flow behavior is necessary. A flow model is developed and applied in order to analyze the steady-state heat transfer system. The introduction of this flow model has been found very effective in expressing the thermal mixing process in an agitated tank with a helical ribbon impeller.
\end{abstract}

\section{Introduction}

An agitated tank is one of the most common types of mixers or reactors for treating highly viscous liquids in the chemical and food industries. The main purpose of agitation is to ensure uniformity of concentration and temperature in the tank. For attaining this purpose, close-clearance impellers such as anchor and helical ribbon impellers are often used. Some investigators ${ }^{1,2,6,7,10)}$ have reported a degree of unavoidable non-uniformity in temperature in the case of laminar flow, even with agitation by closeclearance impellers. Most workers, however, neglected the non-uniformities in bulk temperature for lack of precise information about them and correlated heat transfer coefficients with operational variables under the conventional approximation that the bulk was in a state of thermally perfect mixing. This conventional method must sometimes entail considerable inaccuracies in correlating heat transfer coefficients, and negligence of the non-uniformities in bulk temperature in the design of polymer reactors will have serious consequence in their application.

To obtain an accurate correlation of heat transfer coefficients and to predict the temperature distributions, it is necessary to clarify the relation between heat transfer and fluid flow in the agitated tank. For this purpose, a method which makes it possible to visualize the temperature distributions in an agitated

Received December 3,1980. Correspondence concerning this article should be addressed to S. Saito. M. Ohta is now with Idemitsu Petrochemical Co. Ltd., Ichihara 299-01. K. Yanagwa is now with Sumitomo Metal Ind., Ltd., Wakayama 640 . tank would be very effective. The usual methods of visualization of temperature distributions, such as the schlieren, Moiré and Mach-Zender, give information on temperature variations integrated along the path of light. These methods are, therefore, considered not to be suitable for observation of complex threedimensional temperature distributions such as those in an agitated tank. In this work, liquid crystals were adopted for the visualization of temperature distributions. On the basis of observation, a flow model was proposed to express the relation between heat transfer and flow pattern.

\section{Observation of Temperature Distributions and Flow} Patterns

\section{1 Visualization procedure}

Some kinds of liquid crystals change their colors depending on the environmental temperature. In this work, a mixture of cholesteric liquid crystals encapsulated in gelatine was used. The capsules, commercially available, were 10 microns in diameter and $1.04 \times 10^{3} \mathrm{~kg} / \mathrm{m}^{3}$ in density. In advance, they were homogeneously dispersed at 0.1 to 0.2 volume \% in an aqueous solution of corn syrup. This liquid, which has a viscosity of $1.4 \mathrm{~kg} / \mathrm{m} \cdot \mathrm{sec}\left(\right.$ at $30^{\circ} \mathrm{C}$ ), a density of $1.4 \times 10^{3} \mathrm{~kg} / \mathrm{m}^{3}$, a heat capacity of $2.2 \times$ $10^{3} \mathrm{~J} / \mathrm{kg} \cdot{ }^{\circ} \mathrm{C}$, and a thermal conductivity of $0.36 \mathrm{~J} / \mathrm{m}$. $\mathrm{sec} \cdot{ }^{\circ} \mathrm{C}$, was used for the following visualization experiments.

The unsteady heat transfer approach was adopted and temperature distributions in the transient state were observed. A schematic diagram of the ap- 

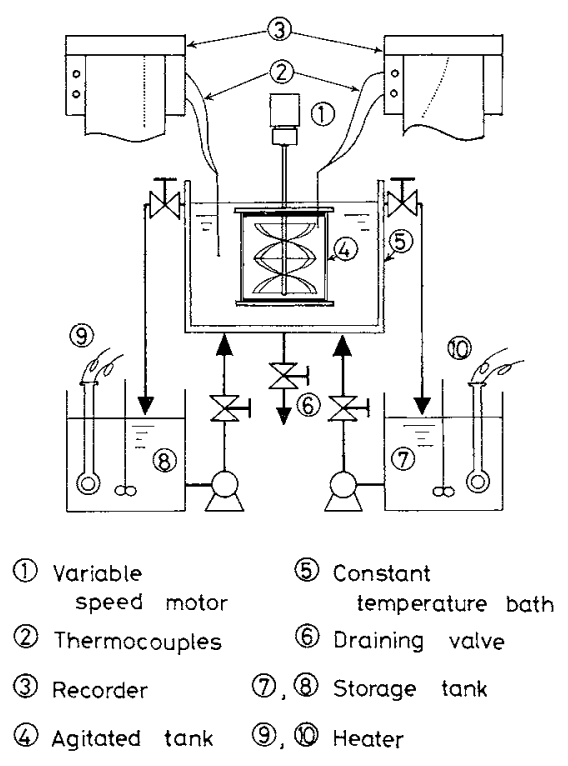

Fig. 1 Apparatus for visualization experiment

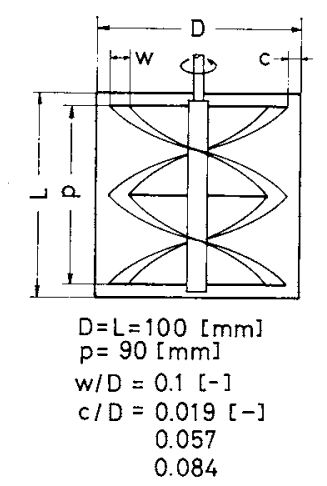

Fig. 2 Dimensions of agitated tank

paratus is shown in Fig. 1. The agitated tank was filled with the liquid, immersed in a constant-temperature bath (5) and brought to the desired initial temperature. Unsteady heat transfer started when the water in the bath (5) was replaced by cooling or heating water.

Figure 2 shows details of the agitated tank and the helical ribbon impeller. The tank was made of a transparent glass cylinder with a flat bottom and a flat lid. Both the bottom and lid were thermally insulated with bakelite boards to allow heat to flow only through the side wall. The impeller blades were made of transparent acrylic resin so that observation of temperature distributions might not be impaired. Impellers of three different diameters were used to examine the effects of clearance between blade and vessel wall on temperature distribution, because clearance was considered to be one of the most important geometrical variables.

Figure 3 shows the optical layout. A light source with a 300-watt xenon lamp produced a vertical plane light beam $3 \mathrm{~mm}$ in thickness and $100 \mathrm{~mm}$ in height.

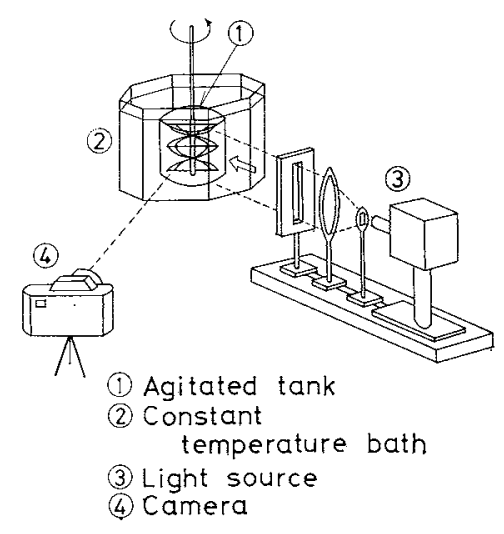

Fig. 3 Layout of optical system

The strength and wavelength of light scattered from the liquid crystals depend on the angle between the plane beam and the direction of observation. Since the best observation was obtained at an angle of 45 deg. from the plane beam, a camera was placed at this position. A regular octagonal constant-temperature bath was used to reduce optical distortion. Photographs were taken with a Nikon F2 Camera with a f3.5 Micro-NIKKOR-P Auto $55 \mathrm{~mm}$ lens, using Kodak ASA 400 film. A long exposure time of $1 \mathrm{sec}$ was required due to the low exposure value of the scattered light. Agitation was interrupted during exposure. It was, however, confirmed that this interruption scarcely affected temperature distribution.

Photographs displaying the changes in color of the light scattered by the liquid crystal in the tank according to temperature are given in Fig. 4. The color changes from red to deep blue as temperature rises from 30 to $38^{\circ} \mathrm{C}$. Below about $30^{\circ} \mathrm{C}$, the liquid crystal used here is colorless and transparent, and hence the photograph appears almost black.

\subsection{Typical temperature distributions}

Photographs of color distributions, that is, of temperature distributions for each impeller, are shown in Fig. 5. This figure shows the results obtained from the heating experiments and lists the experimental conditions. In this figure, $\theta$ represents elapsed time. The rotational speed of the impeller is $15 \mathrm{rpm}$ for each run and the direction of rotation is that causing the blade to pump the liquid upwards.

Figure 6 shows a sketch of the primary circulation flow $^{3)}$ due to the pumping action of the ribbon and its cross view in the illuminated vertical plane. This figure is very helpful in understanding the transitions of temperature distributions shown in Fig. 5. As the primary circulation flows are similar, in spite of the size of clearance betewen the outer edge of the blade and the wall, the transient patterns of temperature distributions are approximately similar.

Initially, a thin layer with a steep temperature gradient is observed on the vessel wall, the thickness 


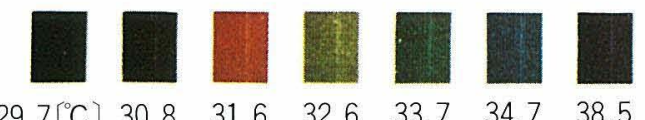

Fig. 4 Changes in color of light scattered by liquid crystal according to temperature

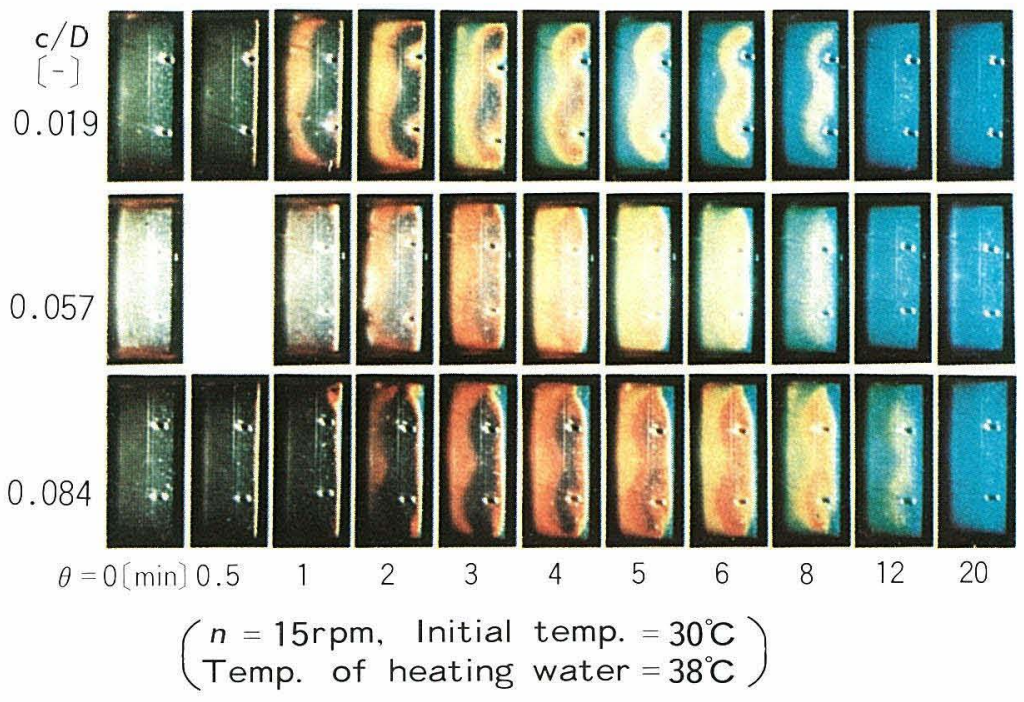

Fig. 5 Visualization of temperature distributions in unsteady heating experiments

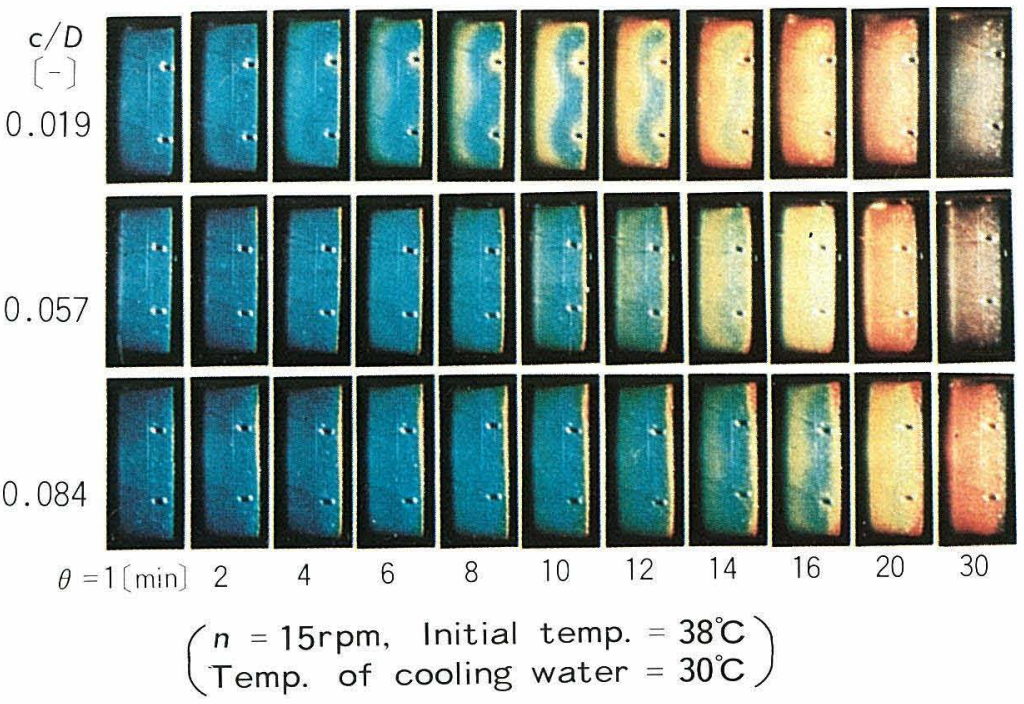

Fig. 7 Visualization of temperature distributions in unsteady cooling experiments 


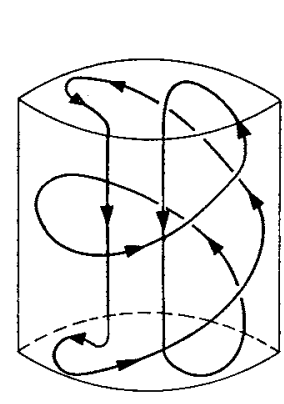

(1) Flow pattern reported by Nagata et al.

Fig. 6 Primary circulation flow

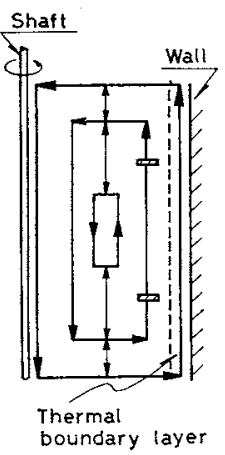

(a) Construction of flow paths

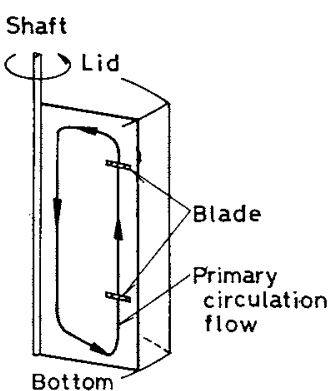

(2) View of section illuminated by plane light beam
Fig. 8 Development of flow model

of the layer increasing in the vicinity of the blades. It is clear that at this stage of the experiment the ratio of the volume of the layer to the total volume of the tank should not be neglected. Subsequently, the fluid near the shaft begins to become red from top to bottom. It should be noted that this color change results mainly from upward flow in the thermal boundary layer on the wall. When the fluid near the bottom corner begins to be colored, both the existence of the flow passing around behind the blades and the strong pumping action of the blades become clearly recognizable from the movement of the colored fluid around the blades. Due to the primary circulation flow originating from the strong pumping action, the region alongside the shaft is rapidly colored. The central core region, however, is colored slowly, and this inner circulation region is distinguishable from the others by its color until thermal equilibrium is almost reached. This suggests that its exchange flow with the outer circulation is small and that the inner circulation sometimes produces an unmixed zone.

Detailed observations reveal some effects of clearance on heat transfer. The thermal boundary layer thickness increases and the rate of heat transfer decreases as clearance widens. It is also clear from photographs of medium- and of widest-clearance im- pellers that the thermal boundary layer develops from bottom to top, since it becomes thicker in the upward direction. Another effect of clearance is the difference in the degree of temperature distributions in the bulk. From the color distributions, the mediumclearance impeller is seen to be superior to the others in producing bulk temperature uniformity. This suggests that there may be an optimum clearance for a helical ribbon impeller mixing process.

Figure 7 on colored page shows photographs obtained from the cooling experiments. The patterns of temperature distributions are quite similar to those obtained from the heating experiments and the same results are obtained.

\section{3 Conclusions from the visualization experiment}

From the above observations, it may be concluded that heat transfer in a highly viscous liquid in an agitated tank is attributable to the following two processes:

1) Convective heat transfer by the circulation flows, which controls both the temperature distribution in the bulk and the renewal of the liquid in the thermal boundary layer at the wall.

2) Heat transfer at the vessel wall.

\section{Development of a Flow Model}

The concept of the flow model developed in this work is shown in Fig. 8.

Figure 8 (a) shows the construction of the circulation paths. It is considered that a flow model must have at least two interconnected circulation paths. One passes through the thermal boundary layer and the other between blades. The flow in the former renews the liquid in the thermal boundary layer and transports the heat gained from the wall to the region at the shaft and to the latter path. The temperature at the wall side of the latter, $t_{\infty}$, may be considered the characteristic temperature and is used to define the heat transfer coefficients at the wall. In addition to these two circulation paths, an inner circulation path should be taken into consideration. Although the flow in this inner circulation path affects the temperature distributions in the transient state, it has no great effect on the heat transfer at the wall and can thus be neglected when non-uniformity in bulk temperature is not great.

Figure 8 (b) shows a model for the heat flux at the wall. Assuming that the thermal boundary layer develops upwards from the bottom, and then its velocity and temperature distributions are represented respectively by linear and cubic forms, as shown in Fig. 8(b), the average heat flux at the wall is expressed as follows ${ }^{8}$.

$$
q=0.80\left(t_{\infty}-t_{W}\right)\left(\frac{\lambda}{l}\right)\left(\frac{l U \rho}{\mu} \cdot \frac{C_{p} \mu}{\lambda} \cdot \frac{l}{c}\right)^{1 / 3}
$$


Employing tank diameter, $D$, instead of $l$ as a characteristic length for the heat transfer surface and assuming $U$ to be proportional to the product of rotational speed, $n$, and pitch of the blade, $p$, the averaged Nusselt number, $N u$, is given as follows:

$$
N u=\frac{h D}{\lambda}=0.80 \gamma\left(\operatorname{Re} \cdot \operatorname{Pr} \cdot \frac{D^{2} p}{d^{2} c}\right)^{1 / 3}\left(\frac{\mu_{W}}{\mu}\right)^{-0.2}
$$

where the viscosity ratio, $\left(\mu_{W} / \mu\right)^{-0.2}$, is introduced empirically following previous workers, and $\gamma$ is a constant which may depend on geometrical variables.

Verification of this model requires quantitative measurements of the heat transfer rate and temperature distributions in an agitated tank. Thus the following quantitative heat transfer experiments were carried out.

\section{Application of the Flow Model}

\subsection{Quantitative heat transfer measurements}

Heat transfer measurements were carried out under steady-state condition in a flow-through system. The designs of the agitated tank and the impeller are shown in Fig. 9. The tank consisted of eight hollow stainless steel cylinders $20 \mathrm{~mm}$ thick and $20 \mathrm{~mm}$ high insulated from each other by $2 \mathrm{~mm}$ thick rubber sheets. Three copper-constantan thermocoulpes $0.2 \mathrm{~mm}$ in diameter were inserted into each cylinder to measure the radial temperature gradient in each wall as shown in the figure. The lid and bottom were thermally insulated with bakelite boards to allow the heat to flow only through the side wall. Prior to the main experiments, two kinds of bottom plates were tested to discover the effect of fluid inlet hole location on the rate of heat transfer and temperature distribution in the bulk. One had only one $12 \mathrm{~mm}$-diameter inlet hole, located at a radius of $40 \mathrm{~mm}$ from the center, while the other had twelve $1.5 \mathrm{~mm}$-diameter inlet holes located symmetrically around the center as shown in Fig. 9. Since no differences in heat transfer characteristics between plates were observed, most runs were carried out with the multi-hole bottom plate.

Impellers of three different diameters were used and their geometrical parameters are listed in the same figure. Twenty thermocouples were fixed on piano wires attached to the blades as shown in Fig. 10 and conducted through the inside of the shaft to slip ringbrush arrangements.

An aqueous solution of corn syrup was forced into the tank from the bottom and allowed to pass out from the top. The flow rate was about $100 \mathrm{cc} / \mathrm{min}$, which corresponded to about half an hour in spacetime in the tank. With the establishment of steady state, inlet and outlet temperatures, each temperature gradient in each part of the side wall, and the bulk

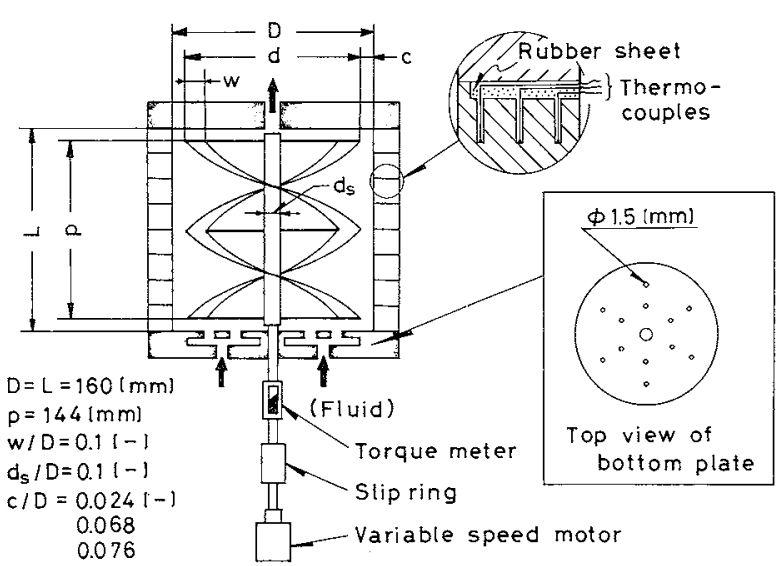

Fig. 9 Designs of agitated tank and impeller

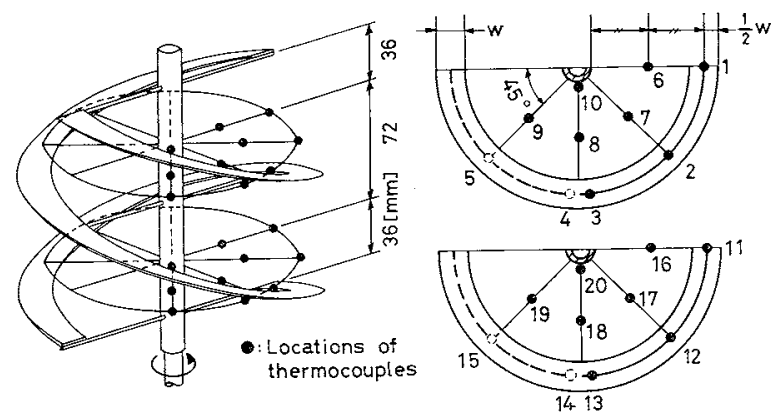

Fig. 10 Illustration of impeller and locations of thermocouples

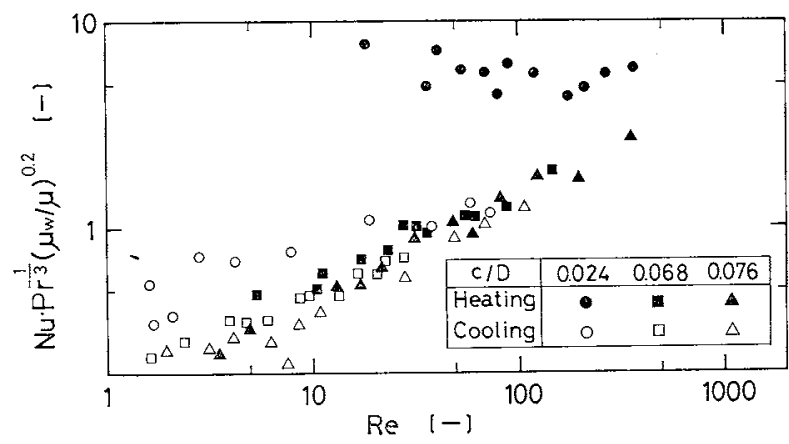

Fig. 11 Correlation of heat transfer coefficients (in the conventional manner)

temperatures at the twenty locations shown in Fig. 10 were measured. The local heat fluxes through each part of the wall and the local temperatures on each inside surface were determined from the temperature gradients measured in the wall. Averaging these local values, we obtained the heat flux and the wall temperature for each run.

At first, the heat transfer coefficients were correlated according to the conventional assumption that the tank was in a state of thermally perfect mixing. The outlet temperature measured was taken to be the characteristic temperature. The results are shown in Fig. 11 in the usual manner ${ }^{4-6)}, \mathrm{Nu} \cdot \mathrm{Pr}^{-1 / 3} \cdot\left(\mu_{W} / \mu\right)^{0.2}=$ $f(R e)$. It is evident that experimental data do not correlate well for every impeller, especially for the 


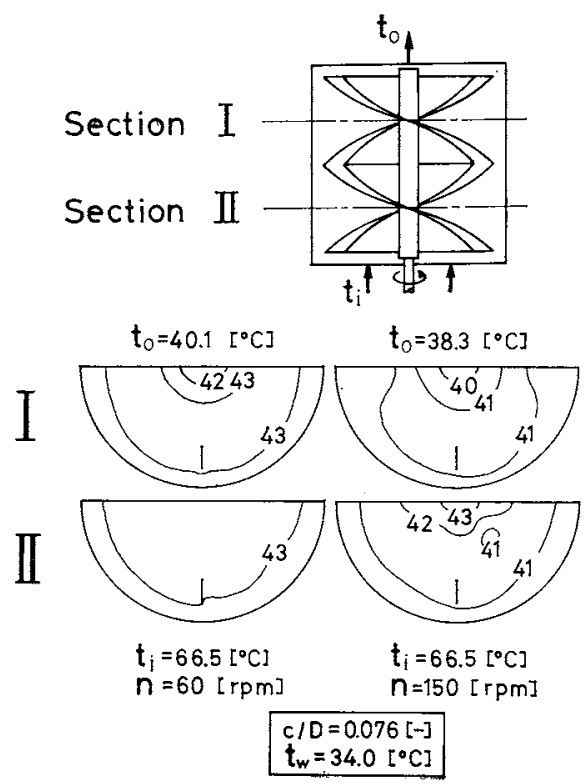

Fig. 12 Typical temperature distributions in horizontal planes of tank

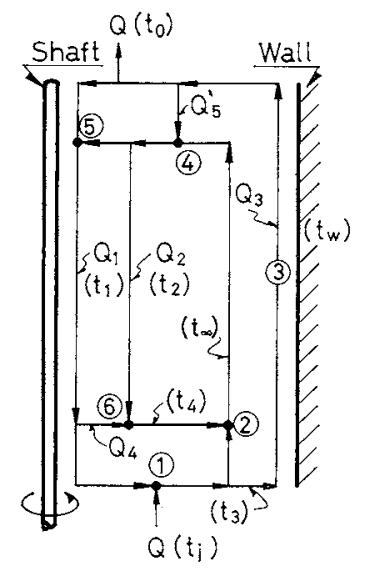

Fig. 13 Flow model for flow-through system

impeller with a $c / D=0.024$ clearance ratio, and that the scatter of data increases with decreasing Reynolds number. From this figure, it may be concluded that the conventional technique which is based on the assumption of perfect mixing cannot provide accurate correlations.

Typical temperature distributions in the horizontal planes of the tank are shown in Fig. 12. This figure shows the isothermal lines which were obtained from cooling experiments. Some degree of non-uniformity in temperature apparently exists in the bulk near the shaft even in the region of high rotational impeller speed. It is also noted that in each case the outlet temperature is lower than that in the bulk. These facts can be explained by the existence of the flow through the thermal boundary layer as shown in the model.

\section{2 Quantitative treatment of the flow model}

The flow model has been applied to the analysis of the steady-state heat transfer system. Figure $\mathbf{1 3}$ shows the description of the model proposed in this work, which has inlet and outlet flows. The inner circulation flow shown in Fig. 8 can be neglected because non-uniformity in the annular region between the shaft and the blade is not great, as shown in Fig. 12. In this figures, $Q_{1}$ to $Q_{5}$ represent the volumetric flow rates, and $t_{1}$ to $t_{4}$ and $t_{\infty}$ represent the temperature in each flow path. $Q$ represents inlet flow rate, and $t_{i}$ and $t_{o}$ inlet and outlet temperatures, respectively. Since in this model heat transfer through the wall results in a temperature change in the fluid in the path (3), the steady-state heat balances at locations (1) to (6) can be expressed as follows.

$$
\begin{aligned}
& \text { (1) } Q t_{i}+\left(Q_{1}-Q_{4}\right) t_{1}-\left(Q+Q_{1}-Q_{4}\right) t_{3}=0 \\
& \text { (2) }\left(Q+Q_{1}-Q_{3}-Q_{4}\right) t_{3}+\left(Q_{2}+Q_{4}\right) t_{4} \\
& -\left(Q+Q_{1}+Q_{2}-Q_{3}\right) t_{\infty}=0 \\
& \text { (3) } \rho C_{p} Q_{3}\left(t_{3}-t_{o}\right)=\Psi \\
& \text { (4) } Q_{5} t_{0}+\left(Q+Q_{1}+Q_{2}-Q_{3}\right) t_{\infty} \\
& -\left(Q+Q_{1}+Q_{2}-Q_{3}+Q_{5}\right) t_{2}=0 \\
& \text { (5) }\left(Q+Q_{1}-Q_{3}+Q_{5}\right) t_{2} \\
& +\left(Q_{3}-Q-Q_{5}\right) t_{0}-Q_{1} t_{1}=0 \\
& \text { (6) } Q_{4} t_{1}+Q_{2} t_{2}-\left(Q_{2}+Q_{4}\right) t_{4}=0
\end{aligned}
$$

In the above equations, $\rho, C_{p}$ and $Q$ are known and $\Psi$ is obtained as a known function of operational variables if a correlation for the heat transfer coefficients at the wall is given. Thus, the temperatures, $t_{1}$ to $t_{4}$ and $t_{\infty}$ and $t_{o}$ can be determined through solutions to the above equations when the flow rates, $Q_{1}$ to $Q_{5}$, are given. In this work, the values of $Q_{1}$ to $Q_{5}$ are determined from the following equations.

$$
\begin{gathered}
Q_{1}=\frac{\beta_{1} Q_{z}}{1+\beta_{1}} \\
Q_{2}=\frac{Q_{z}}{1+\beta_{1}} \\
Q_{3}=\frac{\beta_{2} G\left(Q_{1}-Q_{4}+Q\right)}{1+\beta_{2} G} \\
Q_{4}=\frac{Q_{1}}{1+\beta_{3}\left(Q_{1}+Q\right) / Q_{1}} \\
Q_{5}=-\frac{Q_{3}}{1+\beta_{4}\left(Q_{3}+Q\right) / Q_{3}}
\end{gathered}
$$

In the above equations, $\beta_{1}$ to $\beta_{4}$ are model parameters and $Q_{z}$ in Eqs. (4) and (5) is the overall flow rate of axial downward flow and is equal to the sum of $Q_{1}$ and $Q_{2}$. The values of $Q_{z}$ are obtained from the experimental data of Takahashi $^{9}$ and are expressed for each impeller as

$$
\frac{Q_{z}}{n d^{3}}=\left\{\begin{array}{l}
0.160(c / D=0.024) \\
0.164(c / D=0.068) \\
0.157(c / D=0.076)
\end{array}\right.
$$

The mixing of inlet flow with bulk is considered to 
be promoted by an increase in the inlet flow rate, $Q$. It is assumed that this effect is represented by decreases of $Q_{4}$ and $Q_{5}$ as shown in Eqs. (7) and (8). The inlet and circulating streams combine at point (1) and the resultant flow splits into two flows near the entrance of the thermal boundary layer. One joins the bulk flow and the other the thermal boundary layer. Assuming that the ratio of these two flow rates is equal to that of their flow areas, $Q_{3}$ may be expressed by Eq. (6). In this equation, $G$ is the characteristic length proportional to the averaged thickness of the thermal boundary layer and may be given by the following equation, derived from the model shown in Fig. 8(b).

$$
G=\sqrt[3]{\alpha c D / p n}
$$

The values of $\beta_{1}$ to $\beta_{4}$ should be determined so that the temperatures calculated from Eq. (3) agree with the experimental ones. The experimental values of $t_{\infty}, t_{1}$ and $t_{2}$ are reached by averaging the measured local temperatures as follows.

$$
\left.\begin{array}{rl}
t_{\infty \text { exp }}= & \left\{\left(t_{(1)}+t_{(2)}+\cdots+t_{(5)}\right)\right. \\
& \left.+\left(t_{(11)}+t_{(12)}+\cdots+t_{(15)}\right)\right\} / 10 \\
t_{1 \exp }= & \left(t_{(10)}+t_{(20)}\right) / 2 \\
t_{2 \exp }= & \left\{\left(t_{(6)}+t_{(7)}+t_{(9)}\right)+\left(t_{(16)}+t_{(17)}+t_{(19)}\right)\right\} / 6
\end{array}\right\}
$$

where $t_{(1)}$ to $t_{(20)}$ represent the local temperatures at locations 1 to 20 as shown in Fig. 10. The best fitted values of $\beta_{1}$ to $\beta_{4}$ are obtained as $0.064,8.0 \times$ $10^{2} / \mathrm{m}, 2.0$, and 1.0 , respectively.

\section{3 Correlation of heat transfer coefficients}

The average heat transfer coefficient is correlated by using $t_{\infty}$ calculated from the model with use of the best fitted values for $\beta_{1}$ to $\beta_{4}$ and measured $\Psi$ and is shown in Fig. 14. In this figure, all the experimental results obtained from heating and cooling experiments correlate well. The solid line represents the final correlation, which is obtained by taking $\gamma=0.8$ in Eq. (2).

\section{4 Estimation of temperatures in the tank}

Using the flow model with known parameters and correlated heat transfer coefficients, it is possible to estimate the heat transfer rate and temperature in each flow path. The calculated results of $t_{0}, t_{\infty}, t_{1}$ and $t_{2}$ can be compared with the corresponding measured temperatures. Figure $\mathbf{1 5}$ shows the comparisons between the calculated and the measured temperatures, which are shown to agree well.

\section{Conclusions}

1) Non-uniformities in temperature in an agitated tank can never be neglected in the laminar flow region.

2) Consequently, a flow model realistic enough to represent actual flow behavior is necessary to express

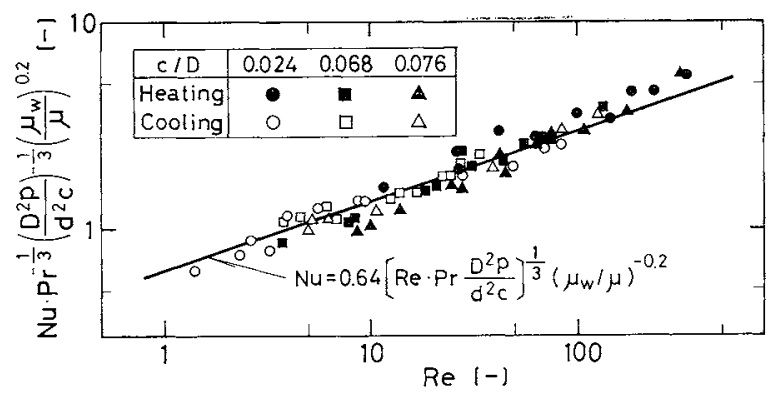

Fig. 14 Correlation of heat transfer coefficients (by means of the flow model)

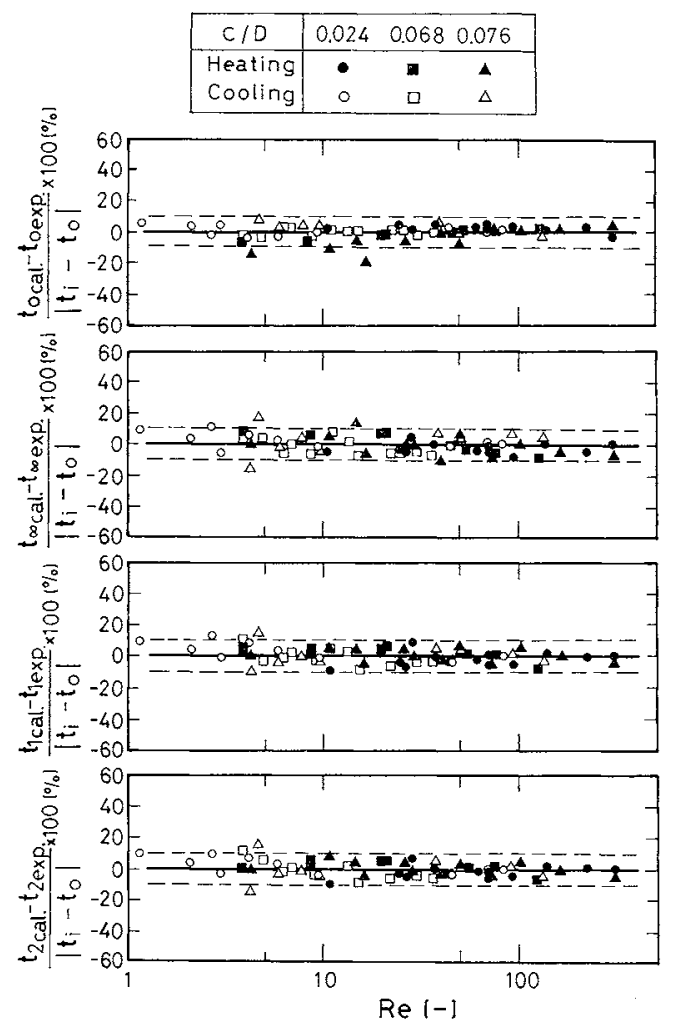

Fig. 15 Comparisons between calculated and measured temperatures

quantitatively the thermal mixing process.

\section{Acknowledgments}

This work was supported by the Science Research Foundation of the Ministry of Education, Science and Culture, Japan, Grant No. 485232.

The authors wish to express their thanks to the Asahi Glass Foundation for its financial support.

\section{Nomenclature}

$\begin{array}{llr}C_{p} & =\text { specific heat } & {\left[\mathrm{J} / \mathrm{kg} \cdot{ }^{\circ} \mathrm{C}\right]} \\ c & =\text { clearance between blade tip and tank wall } & {[\mathrm{m}]} \\ D & = & \text { inside diameter of tank } \\ d & =\text { outside diameter of impeller } & {[\mathrm{m}]} \\ G & =\text { characteristic length defined by Eq. }(10) & {[\mathrm{m}]} \\ h & =\text { heat transfer coefficient } & {\left[\mathrm{J} / \mathrm{m}^{2} \cdot \mathrm{sec} \cdot{ }^{\circ} \mathrm{C}\right]} \\ L & =\text { depth of tank } & {[\mathrm{m}]} \\ l & =\text { characteristic length of heat transfer } & \\ & \text { surface } & {[\mathrm{m}]}\end{array}$ 


\begin{tabular}{|c|c|c|c|c|}
\hline $\mathrm{Nu}$ & $=$ Nusselt number $(=h D / \lambda)$ & {$[-]$} & $\mu$ & $=$ viscosity at bulk temperature \\
\hline$n$ & $=$ rotational speed of impeller & {$[1 / \mathrm{sec}]$} & $\mu_{W}$ & $=$ viscosity at wall temperature \\
\hline $\operatorname{Pr}$ & $=$ Prandtl number & {$[-]$} & $\lambda$ & $=$ thermal conductivity \\
\hline$p$ & $=$ pitch of impeller & {$[\mathrm{m}]$} & $\rho$ & $=$ density \\
\hline$Q, Q_{1}, Q_{2}$, & $Q_{3}, Q_{4}, Q_{5}=$ volumetric flow rates & {$\left[\mathrm{m}^{3} / \mathrm{sec}\right]$} & $\Psi$ & $=$ rate of heat transfer at the wall \\
\hline$Q_{z}$ & $\begin{aligned}= & \text { over all flow rate of axial circulation } \\
& \text { flow }\left(=Q_{1}+Q_{2}\right)\end{aligned}$ & {$\left[\mathrm{m}^{3} / \mathrm{sec}\right]$} & \multicolumn{2}{|c|}{ Literature Cited } \\
\hline q & $=$ average heat flux in Eq. (1) & {$\left[\mathrm{J} / \mathrm{m}^{2} \cdot \mathrm{sec}\right]$} & 1) & Coyle, C. K., H. E. Hirshland, B. J. Michel, and Y.J. \\
\hline $\operatorname{Re}$ & $=$ Reynolds number $\left(=d^{2} n \rho / \mu\right)$ & {$[-]$} & & Oldshue: Can. J. Chem. Eng., 48, 275 (1970). \\
\hline & $=$ local temperature & {$\left[{ }^{\circ} \mathrm{C}\right]$} & 2) & Mizushina, T., R. Ito, S. Hiraoka, Y. Konaka, and $\mathbf{J}$. \\
\hline$t_{\infty}$ & $=$ bulk temperature & {$\left[{ }^{\circ} \mathrm{C}\right]$} & & Watanabe: Kagaku Kögaku, 31, 1208 (1967). \\
\hline$t_{W}$ & $=$ wall & {$\left[{ }^{\circ} \mathrm{C}\right]$} & 3) & Nagata, S., M. Yanagimoto and T. Yokoyama: ibid., 21, \\
\hline$t_{i}, t_{o}$ & $=$ inlet and outlet temperatures & {$\left[{ }^{\circ} \mathrm{C}\right]$} & & $278(1957)$ \\
\hline$t_{(1)}$ to $t_{(20)}$ & $\begin{array}{l}=\text { local temperatures measured at locatio } \\
1 \text { to } 20 \text { shown in Fig. } 10\end{array}$ & {$\left[{ }^{\circ} \mathrm{C}\right]$} & 4) & $\begin{array}{l}\text { Nagata, S., M. Nishikawa and T. Kayama: J. Chem. Eng. } \\
\text { Japan, 5, } 83 \text { (1972). }\end{array}$ \\
\hline$U$ & $=$ velocity at $y=c$ in Fig. 8 (b) & {$[\mathrm{m} / \mathrm{sec}]$} & 5) & Nagata, S., M. Nishikawa and T. Kayama: ibid., 5, 187 \\
\hline$u$ & $=$ local & {$[\mathrm{m} / \mathrm{sec}]$} & & $(1972)$ \\
\hline$y$ & $\begin{array}{l}=\text { distance from tank wall } \\
=\text { distance from tank bottom }\end{array}$ & $\begin{array}{l}{[\mathrm{m}]} \\
{[\mathrm{m}]}\end{array}$ & 6) & $\begin{array}{l}\text { Nishikawa, M. and N. Kamata: Kagaku Kogaku Ron- } \\
\text { bunshu, 1, } 466 \text { (1975). }\end{array}$ \\
\hline & $=$ distance from tank bottom & {$[\mathrm{m}]$} & 7) & Pollard, J. and T. A. Kantyka: Trans. Instn. Chem. Engs., \\
\hline & $=$ therm & {$\left[\mathrm{m}^{2} / \mathrm{sec}\right]$} & & \\
\hline$\beta_{1}, \beta_{3}, \beta_{4}$ & $\begin{array}{l}=\text { adjustable constants in Eqs. (4), (5), } \\
(7) \text { and (8) }\end{array}$ & {$[-]$} & 8) & $\begin{array}{l}\text { Shilichting, H.: "Boundary Layer Theory (6th Ed.)", p. } \\
\text { 291, McGraw-Hill (1968). }\end{array}$ \\
\hline$\beta_{2}$ & $=$ adjustable constant in Eq. (6) & {$[1 / \mathrm{m}]$} & 9) & Takahashi, K.: Master Thesis, Tohoku Univ. (1977). \\
\hline & $=$ adjustable constant in Eq. (2) & {$[-]$} & 10) & Zlokarnik, M.: Chem. Ing. Tech., 41, 1195 (1969). \\
\hline & $=$ thickness of thermal boundary layer & {$[\mathrm{m}]$} & & \\
\hline
\end{tabular}

\title{
PRETREATMENT OF CELLULOSIC MATERIALS FOR DIGESTION BY RUMINOCOCCUS ALBUS
}

\author{
Masahito TAYA, KaZuHisa HONMA, Kunio OHMIYA, \\ TAKESHI KOBAYASHI AND SHOICHI SHIMIZU \\ Department of Food Science and Technology, \\ Faculty of Agriculture, Nagoya University, Nagoya 464
}

\begin{abstract}
The effects of chemical pretreatment on cellulose digestion by a cellulolytic anaerobe, $R u$ minococcus albus, were examined. Pretreatment with $\mathrm{H}_{3} \mathrm{PO}_{4}$ was the most effective for digestion of crystalline cellulose by $R$. albus of the four pretreatment methods investigated. The best condition for pretreatment of Avicel with $\mathrm{H}_{3} \mathrm{PO}_{4}$ was as follows; $\mathrm{H}_{3} \mathrm{PO}_{4}$ concentration: 85-100 (v/v) $\%$; treatment time: over $5 \mathrm{~min}$; treatment temperature: $0^{\circ} \mathrm{C}$ at $85(\mathrm{v} / \mathrm{v}) \% \mathrm{H}_{3} \mathrm{PO}_{4}$ or $0-60^{\circ} \mathrm{C}$ at $95(\mathrm{v} / \mathrm{v}) \% \mathrm{H}_{3} \mathrm{PO}_{4}$; cellulose concentration: $1-3(\mathrm{w} / \mathrm{w}) \%$. Treatment efficiencies did not decrease after five repeated uses of $\mathrm{H}_{3} \mathrm{PO}_{4}$. For effective digestion of newspaper or rice straw, delignification was essential in addition to swelling with $\mathrm{H}_{3} \mathbf{P O}_{4}$. For newspaper and rice straw which were cryomilled, delignified and swollen with $\mathrm{H}_{3} \mathrm{PO}_{4}$, specific cellulose digestion rates by $R$. albus were 0.081 and $0.099 \mathrm{~g}$ cellulose $/ \mathrm{g}$ dry cells/hr, respectively.
\end{abstract}

\section{Introduction}

Cellulose is produced in most higher plants by the utilization of solar energy and comprises from 20 to $50 \%$ of their dry matter content. In the near future, Received December 4, 1980. Correspondence concerning this article should be addressed to T. Kobayashi. M. Taya and T. Kobayashi are now at Dept. of Chem. Eng., Faculty of Eng., Nagoya Univ., Nagoya 464. cellulose may become an important carbon and energy resource for microbial growth if it can be hydrolyzed to glucose. So far, cellulases from fungi have been intensively applied to the hydrolysis of cellulosic wastes such as rice straw, newspaper and wood $^{1,2,5,17,18)}$. However, such wastes are resistant to enzymatic attack because of the crystallinity of 